\title{
Learning from adverse events
}

\author{
A. S. Zigmond
}

\begin{abstract}
"Experience is of no ethical value. It is merely the name men give to their mistakes" Oscar Wilde (The Picture of Dorian Grey).
\end{abstract}

Whenever colleagues meet it seems there is discussion about the latest inquiry into suicides or homicides. One cannot turn on the television without the news or a documentary referring to the latest tragedy. Risk assessment and defensible documentation are commonly the subjects of lectures and symposia. Lessons are learned, or not, from published inquiries and associated media attention. The attribution of blame is always high on the agenda. Yet when visiting psychiatric services and talking to staff I am usually impressed by their professionalism and staggered by their workload.

It is not surprising that consultants are becoming increasingly upset and angry at the personal criticism and are responding to the reports with pleas about workload, shortage of beds and community resources and deficiencies in the legislation. When reading inquiry reports, or taking part in an inquiry, I cannot help feeling the appropriateness of at least some of the criticisms. It is true that reports ought to acknowledge understaffing, legal inadequacies and so on. Psychiatrists should not be used as scapegoats nor be held responsible unfairly for the behaviour of others. Equally, we must not be dismissive of valid criticisms.

In assessing the care given to a patient, for example, determining risks presented by the patient, it seems to me that psychiatrists emphasise different items from those looked at by an inquiry team. The former look at diagnosis, psychiatric history, forensic history, social history and circumstances, illicit drug use, past suicidal or homicidal thoughts or behaviour and so on, looking for predictors of certain behaviours. The latter looks at the process of the interaction between the patient and the services and of one group of services with another. Inquiry teams are much more likely to be concerned about inconsistencies within patients' records or reports than to question original data or opinions.

It might be helpful to look at some issues raised in a number of inquiries and clinical audits following patient suicides and homicides.

\section{Issues}

\section{Communication}

There should always be clear and effective lines of communication. These should detail who should be informed, by whom, of what and under what circumstances.

A record of interviews with patients, including the history, mental state examination, patients' answers to questions about suicide risk, the doctors' view of the suicide risk and the steps to be taken to minimise the risk are (or should be) recorded in the medical notes. There are particular occasions when errors in, or failures of, communication are more common and more likely to have adverse consequences.

\section{Transfer from out-patient to in-patient care}

Doctors rarely read nursing notes. It is not unusual to see clear statements about suicide risk in medical notes written in the out-patient clinic with no equivalent record in the subsequent in-patient nursing notes. Indeed, there may be entries at the time of admission stating that there is no suicide risk or that the medical staff have not reported any suicide risk. This can lead to the patient being placed on a lower level of observation than is appropriate, with obvious dangers.

There are a number of reasons why such discrepancies might occur. Medical notes may be sent to a secretary for letters to be typed or sent by some postal system from the clinic to the in-patient unit. They

A. S. Zigmond is a Consultant Psychiatrist with Leeds Community and Mental Health (Teaching) Services Trust (High Royds Hospital, Menston, Ilkley, West Yorkshire LS29 6AQ), Senior Clinical Lecturer, University of Leeds and a Mental Health Act Commissioner. 
Box 1. Clinical information 1

When a patient's care is transferred from one part of the service to another it is essential all information is transferred with them.

The process for conveying information from those who assess the patient outside the hospital to those responsible for in-patient care needs to be clear.

Both medical and nursing notes should document what decisions have been made, what information has been conveyed and to whom.

may remain in the boot of the doctor's car overnight. In any event the medical notes are sometimes unavailable at the time a patient is admitted, both to the admitting doctor and to the nursing staff. Even when the notes are available nursing staff read medical records with no greater frequency than doctors read nursing records. Thus, information as to risk and level of observation is usually given verbally. Often no record is kept of the conversation. By the time of an inquiry into a patient suicide the details of what the doctor told the nurse may not be readily agreed (Box 1 ).

\section{Transfer from in-patient to out-patient care}

It is not only when a patient is admitted to hospital that there is scope for poor communication. Another danger time is when the patient is discharged and care transfers from the in-patient staff to the community team.

"Details of the signs and symptoms which suggest a likely relapse should be recorded as should details of the steps that the patient would like to be followed in the event of a relapse occurring. An assessment should be made as to whether the patient's propensity for violence presents any risk to his own health or safety or to the protection of the public" (North East Thames \& South East Thames Regional Health Authorities, 1994, p. 110).

A typical scenario might be as follows: a patient has had many admissions to hospital. Each time he is treated his condition improves and he is discharged to out-patient care, and perhaps also to attend a depot clinic. After some months he refuses his medication leading to a deterioration in his mental state. His readmission, sometimes following an act of selfharm or an affray, is highly probable. This story is likely to be familiar to all practising psychiatrists.

What information is given to the clinic nurse and general practitioner (GP)? Always remember that the information is called a 'care plan'. The plan should state that the patient has, in the past, always refused his medication after a period as an outpatient and that he is likely to default again. It should cover whether there is a particular pattern or time-scale and, if so, should give the details. It should state who should be informed and how, and give an indication as to what might reduce the likelihood of this eventuality occurring. The potential consequences should be detailed. If the patient becomes violent or suicidal following cessation of medication should there be an assessment for possible compulsory readmission and, if so, how quickly need this take place? It should be made clear who would be responsible for organising this.

Care plans are commonly restricted to giving details about the follow-up arrangements only. The care plan is an important part of the communication system between different professions and should give helpful, practical information.

It is necessary for services to have systems for collecting, in addition to disseminating, information. There are usually reasonably good mechanisms for collecting, delivering and storing written information. It is important to make sure letters, pathology results and so on are read before they are filed. A signature on the document is satisfactory.

Telephone calls are much easier to 'lose'. Relatives may telephone with important information about a patient's condition. Many inquiry reports record that relatives state they gave information to the clinical team which seemed to be ignored. Relatives ring hospitals at all hours and may be unsure whom to ask for. All patient-related information, including telephone calls, needs to be documented and become part of the clinical record. All hospitals should have systems in place to ensure messages do not get lost.

\section{Review of past history}

Past behaviour is the best predictor of future behaviour. It is sometimes assumed that decisions can be made without a careful review of the patient's

Box 2. Clinical information 2

Are there systems in the hospital to enable clinicians to receive and convey information?

Who should be informed, of what, when and in what form?

Is the correct information easily accessible and available to help others make decisions? 
history. Perhaps we believe we know our patients' histories better than we do. Two common examples are given below.

"Clinical teams gave insufficient weight to the clear history of... Partly this was due to insufficiently rigorous examination of records" (Blom-Cooper et al, 1995).

In-patients who commit suicide sometimes do so having absconded from a ward. It is routine for psychiatrists of all levels to undertake some assessment of the risk of suicide when patients are admitted to hospital and at intervals throughout their stay. One of the reasons for the assessment is to enable a decision to be made on the level of observation required to prevent the patient leaving the ward if it is thought that if the patient were to do so, it would result in an unacceptable risk. This is usually recorded in the medical notes.

For instance, a patient is admitted to a psychiatric ward having threatened to harm himself. A careful psychiatric history reveals the details of his many previous admissions to hospital and his history of self-harming behaviour. Mental state examination confirms both the diagnosis and the severity of his suicidal thoughts. It is decided that he must be confined to the ward (he readily agrees to this) and be placed on a level of observation which requires the nurses to check on him every 15 minutes.

Does a detailed review of the previous history take place? The assessment of risk of self-harm and absconding is often based solely on the current history and mental state examination with little or no attention being paid to the detail of past behaviour available in the clinical record. Are the circumstances of the admission similar to a previous occasion? Is the patient talking and behaving in a similar way? What was done at that time to protect the patient and what was the outcome? It is not unusual to find a clear record of patients absconding, sometimes on quite high levels of observation, and yet this is not taken into account on subsequent admissions. Medical notes usually describe the basis used for determining suicide risk; it is much rarer to read the grounds for determining a particular level of observation for a patient.

No less rigorous scrutiny of previous notes is needed when preparing plans for out-patients.

A typical, and common, problem (as already mentioned) is that of patients failing to continue with medication following discharge from in-patient care. Case notes document many admissions and it is not unusual for the hypothesised reasons for relapse to be described. Refusal to continue with medication is often blamed. It is much less usual to see a review of the circumstances of the patient and details of the medication being prescribed at the time the patient refused to continue with medication. What explanation did the patient give? Was it the same explanation each time? Was the patient asked about side-effects, costs or inconvenience? How often is the patient prescribed the same medication about which they have always complained?

If a patient is known to be reluctant to continue with medication, steps should be taken to minimise the effort that is required by the patient to receive the medication. It should be investigated whether it is easier for the patient to collect a prescription from their GP or from the clinic; whether a greater quantity of medication should be given at any one time and whether to do so would be safe. It is not unknown for patients who are prescribed a depot neuroleptic to be required to collect a prescription from their GP, take the prescription to a retail pharmacist, collect and pay for the medication and take it to the depot clinic for the injection to be given. This would test anybody's motivation.

The repetitive nature of a patient's behaviour is sometimes easily matched by the repetitive nature of the doctor's behaviour. A thorough review of records establishing what has or has not worked would support attempts to try alternative strategies on subsequent occasions (Box 3 ).

Community psychiatric nurses sometimes refuse to give depot medication on the grounds that it spoils the therapeutic relationship. This can often mean that the person is then required to follow the procedure described above. If a consultant objects to this approach, the reasons for doing so need to be documented in order to ensure that they will be considered fully.

Box 3. Decision-making

When interviewing a patient or advising on a situation always review the case notes and answer the following Has this situation arisen before? What was done then? What was the outcome on that occasion?

Record the answers to this review.

If the outcome was good last time and yet you chose to follow a different course of action this time, it is helpful to record your reasons and, in due course, the outcome.

If the outcome was poor last time and yet you follow the same course of action, it is important to record why a different approach was not appropriate. 


\section{Multi-disciplinary decision- making}

\begin{abstract}
"Assessment of risk needs to be a continuing process in which the multi-disciplinary team is repeatedly reappraising the patient's risk of violence... Such a process is not unfamiliar to clinical teams which practice ongoing assessment of suicide risk" (BlomCooper et al, 1995).
\end{abstract}

\section{Ward rounds}

The standard meetings held about in-patients are the ward rounds or multi-disciplinary team meetings. The usual practice is for the meeting to be documented in the case notes by the junior doctor. The name of the consultant or senior doctor undertaking the ward round is recorded.

It is rare for the names of other doctors or the names or grades of nurses or other staff who are present to be recorded. It is assumed that at least the nursing staff will keep their own records (and that the relevant entries will accord with the entries in the medical notes). This assumption is often erroneous. Nurses may make notes for immediate use, which are not kept, or may not make notes at all. They believe the doctors record the ward round. It is not unusual, therefore, to find entries in medical notes headed 'ward round' with the name of the consultant but no evidence of the presence of other disciplines. There may be no relevant entry in the nursing record of the same date.

When I discussed this with colleagues I was told that it is obvious that ward rounds/multi-disciplinary team meetings have representatives from different professions present. I can only report it is not so obvious months or years later, following investigation of an adverse event, in the absence of a written record.

It is valuable to record the contribution of different members of the team and who were present when decisions were made. Indeed it may help to reinforce the case that more staff from differing professions are needed to provide a proper service to patients.

\section{After-care: Section 117 meetings}

It is commonly difficult to find any clear documentation relating to Section 117 After-Care, despite the fact that the provision of such care is a statutory requirement. Where there is documentation it may list who has attended but not who was invited but failed to attend, or, if a particular discipline was not invited, why not. Repeated failure on the part of any individual discipline to attend needs to be addressed effectively.

"Section 117 of the Act (Mental Health Act 1983) requires health and local authorities to provide, in cooperation with relevant voluntary agencies, aftercare services for those discharged under Section 3..." (Department of Health, 1995).

Lack of resources, including personnel, should always be brought to the attention of managers. This should be in writing, asking for a response. If the response is unsatisfactory, the managers should be notified. The expressed concerns must be specific and detailed, as general complaints are not helpful.

\section{Following hospital policies}

All hospitals have policies covering such topics as racial discrimination, admission procedures, observation levels, absence without leave, Section 117 , and the Care Programme Approach (CPA). How many psychiatrists read and keep up-to-date with the policies is questionable. Should something go wrong with a patient's care it is much easier to defend actions if policies were followed (Box 4).

Most hospital policies state that observation levels should be determined jointly between medicine and nursing and recorded in the medical and nursing record. Table 1 shows an example where the hospital policy was clearly not followed. The only defence to this would be if the hospital policy was out of line with national guidance.

"Individual care plans should include a clear statement of the degree of risk of self-harm, what level of observation is warranted to protect the patient and at what interval the level of observation will be reviewed" (Department of Health, 1995).

\begin{tabular}{|c|c|c|}
\hline Date & Medical notes & Nursing notes \\
\hline 10 March & Level three & Level three \\
\hline 11 & 15 minutes & $15-5$ minutes \\
\hline 12 & 5 minutes & No entry \\
\hline 14 & Level one & Level one \\
\hline 18 & 15 minutes & 15 minutes \\
\hline 19 & 30 minutes & No entry \\
\hline 20 & Level three & Level three \\
\hline 27 & $\begin{array}{l}\text { Discretionary } \\
\text { escorted leave }\end{array}$ & $\begin{array}{l}\text { Discretionary } \\
\text { escorted leave }\end{array}$ \\
\hline 04 April & No entry & 30 minutes \\
\hline 03 May & No entry & 30 minutes \\
\hline 04 June & No entry & Level one \\
\hline 05 & No entry & Level one \\
\hline 08 & No entry & Level one \\
\hline 12 & $\begin{array}{l}\text { Unescorted leave } \\
\text { at nurse's } \\
\text { discretion }\end{array}$ & $\begin{array}{l}\text { Unescorted leave } \\
\text { at nurse's } \\
\text { discretion }\end{array}$ \\
\hline 13 & No entry & Level three \\
\hline 15 & 30 minutes & 30 minutes \\
\hline 16 & 'Wishes to die' & No entry \\
\hline
\end{tabular}


"Levels of observation should be jointly reviewed and a record made of agreed decisions" (Department of Health, 1995).

There would be no defence here.

It should also be noted that, for a detained patient, the entry on 12 June (see Table 1) implies unlawful acts, as only the responsible medical officer can authorise leave under the Mental Health Act 1983 and this duty may not be delegated.

All hospitals have a search policy to be followed when patients go missing, including guidance on the process to be followed when a patient leaves the ward without permission. Such policies may identify which categories of patients should cause concern (e.g. those detained under the Mental Health Act, those identified as suicidal, disorientated patients and so on), where staff should search, how they should be deployed, how more staff should be acquired, who should be informed and the steps they, in turn, should take.

Many inquiries, post-incident reports and clinical audits have shown that such policies are not always followed. Staff make judgements based on their view as to why the patient has left the ward rather than following laid down criteria. This would not be so important if it usually led to an increase in the efforts made to find a patient. It is more common for staff to decide that the patient's absence does not warrant further action ('He always goes home/to his mother's/to the park').

Failure to follow hospital policies is considered an internal disciplinary matter in addition to the possibility of leading to serious adverse events.

All hospitals have a policy (sometimes several) for Section 117 After-Care and the CPA. It is not uncommon to find reasonably good after-care being provided, but not in line with the hospital policy. Errors, omissions and adverse events are much harder to defend in these circumstances.

"All detained patients should benefit from the CPA, which is the cornerstone of individual care planning in England" (Mental Health Act Commission, 1997).

\section{Record-keeping}

The following is a typical list of comments taken from inquiry reports. Many other examples could have been used.

(a) We were unable to find a clear record of actions taken when it was realised the patient was no longer on the ward.

(b) We could find no record of this in medical or nursing notes.

(c) Thus there was no evidence of any multidisciplinary review.
Box 4. Hospital policies

At the very least read and follow

Admission procedures

Assessment procedures (if they exist)

Observation levels policies and procedures

Missing patient policies and procedures

CPA, Section 117 and other after-care policies and procedures

(d) The clinical record is confusing and contradictory.

(e) The post-incident report of the doctor includes the quote given in the above note. As stated we can find no documented support for this.

(f) The patient had been detained on Section 3 of the Mental Health Act 1983. We can find no evidence of the operation of Section 117 meeting or a care plan.

(g) We cannot say that such decisions were not made jointly, but they were not clearly documented in the appropriate records.

Record-keeping is essential. It is the key to almost all other activities and undoubtedly enables the defence of actions when things go wrong. It is worth noting that in one instance both the health authority inquiry and that of the area child protection committee found a consultant blameless in the case of a mother killing her baby. He had followed all procedures correctly, had responded to the GP promptly, had informed the GP by telephone and in writing of his assessment and recommendations, and recorded everything in the notes. 'If it wasn't documented, it wasn't done' is the byword of inquiries and courts.

Record-keeping should not be seen purely as defensive. It assists good clinical practice in many ways. Medical notes are the record of a patient's history. The more accurate and complete the record, the easier it will be for us, or colleagues, to make an appropriate risk assessment and plan clinical care in the future. Indeed, the recording of information and the subsequent decisions often act as an aidemémoire for questions to be asked or steps to be taken in the future.

\section{Lessons to be learnt}

When making an assessment of risk it is important to record the basis for both the assessment and for the final decision as to the steps to be taken to 
Box 5. Summary

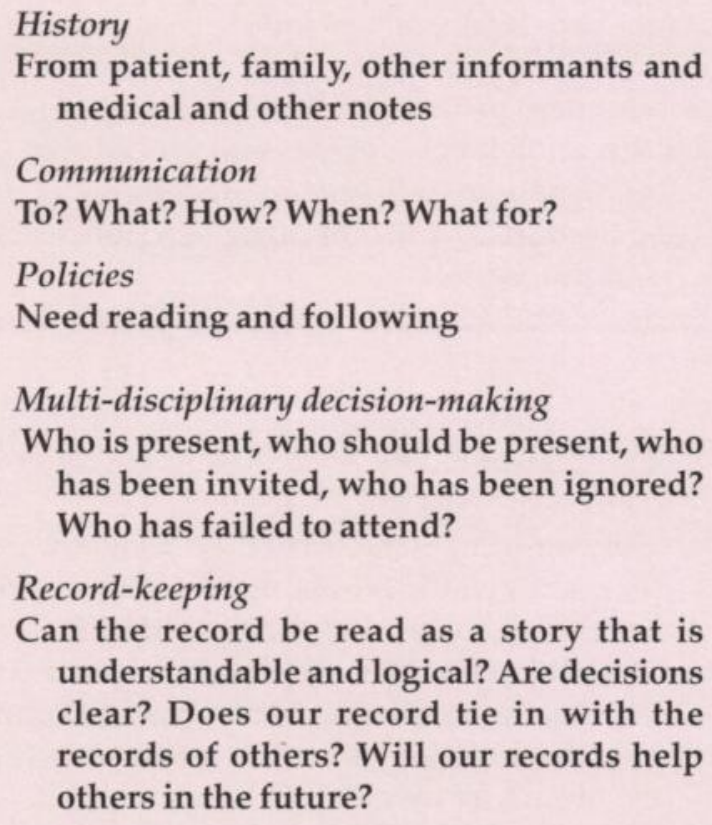

History

From patient, family, other informants and medical and other notes

Communication

To? What? How? When? What for?

Policies

Need reading and following

Multi-disciplinary decision-making

Who is present, who should be present, who has been invited, who has been ignored? Who has failed to attend?

Record-keeping

Can the record be read as a story that is understandable and logical? Are decisions clear? Does our record tie in with the records of others? Will our records help others in the future?

minimise the risk. Sometimes notes may make clear mention of the patient expressing suicidal thoughts and yet there are no, or limited, plans to deal with this. I suspect this is because the psychiatrist often thinks the risk is minimal. If this is so, the grounds for such a belief should be clearly documented.

Risk is often assessed and documented early in the care of the patient, usually on admission, and is not reassessed or documented. It is much more common to see a statement that a patient is at risk of self-harm, with evidence, than to see a statement that the risk has diminished or gone, with evidence.

At the time of taking the clinical examination for membership of the Royal College of Psychiatrists candidates are taught to say that they would review the patient's old notes. In practice we often seem to assume we can remember a patient's history in far greater detail than would seem to be true in reality.

Doctors do not seem to be as conversant with hospital policies as they should be. For example, in most hospitals the 'observation' policy states that the decision about observation levels should be taken jointly by doctors and nurses. There may not be an accurate record of such discussions or their outcome in the medical notes.

If discussions about patients take place over the telephone, a note of the content should be written in the patient's record.

The names, or status, of those attending multidisciplinary meetings such as ward rounds should be recorded.
Awareness of a hospital policy or practice which damages patient care should be reported, in writing, to the senior management of the hospital.

Lack of resources should be documented and reported.

There is much to be learned from both reading and undertaking inquiries. Sympathy for colleagues (which is usually deserved) should not obscure lessons which can be learned and which should take little time, have few cost implications and might improve patient care. It is perhaps less painful to learn from others' mistakes than from one's own.

Services for the mentally ill are under- resourced. We must do the best we can with the resources we are given. The issues raised here can be addressed with little impact on our workload.

\section{References}

Blom-Cooper, L., Hally, H. \& Murphy, E. (1995) The Falling Shadow: One Patient's Mental Health Care 1978-1993. London: Duckworth.

Department of Health (1995) The Health of the Nation. Building Bridges. London: HMSO.

Mental Health Act Commission (1997) Seventh Biennial Report. London: HMSO.

North East Thames \& South East Thames Regional Health Authorities (1994) The Report of the Inquiry into the Care and Treatment of Christopher Clunis. London: HMSO.

\section{Multiple choice questions}

1. Patients' case notes are useful:

a to review past history

b to record decisions, not the basis for these decisions

c to look for outcomes to previous similar situations

d to enable others to criticise us when things go wrong.

2. Communication:

a is not the purpose of the patient's case notes

b between members of a multi-disciplinary team can be taken for granted

c is particularly important at times of admission to, and discharge from, hospital

$\mathrm{d}$ is central to the purpose of a patient's care plan.

3. Medical notes:

a should record the names or disciplines of staff present at ward rounds

b should not include advice about future action to be taken with details of likely circumstances

c need not explain how decisions were made

d should record patients' observation levels. 
4. Your hospital's policies state:

a the senior nurse can increase a patient's observation levels but a doctor must review this decision within two hours

b a doctor must review all patients on the highest level of observation every 24 hours

c on admission all patients will be placed on the lowest level of observation unless otherwise specified

d patients' observation levels must be recorded both in the nursing and in the medical notes

e when detained patients fail to return from leave the responsible medical officer must be informed immediately

f all patients who go absent without leave will be examined by a doctor on return to the ward

$g$ if detained patients are found to have illegal drugs in their possession, it is the responsible medical officer who will decide whether the police are to be informed $h$ it is the responsibility of the responsible medical officer to make sure that all patients are registered under the Care Programme Approach.

\begin{tabular}{llllll}
\multicolumn{6}{l}{ MCQ answers } \\
1 & & 2 & & 3 & \\
a & T & a & F & a & T \\
b & F & b & F & b & F \\
c & T & c & T & c & F \\
d & F & d & T & d & T
\end{tabular}

4 I do not know the correct answers to any of these questions but you should.

\section{Management of Imminent Violence}

\section{Clinical Practice Guidelines to Support Mental Health Services}

Prepared by the College Research Unit, this report publishes the findings of the most comprehensive and systematic review yet of research into the management of violence in clinical settings. It sets guidelines for clinical practice to be implemented in hospitals and psychiatric units throughout the UK and will be of interest to colleagues overseas who are seeking guidance in this area. The guidelines will form the basis of a national multi-centre clinical audit being organised by the College Research Unit later this year.

\section{Key features}

- Guideline statements supported by a series of implementation points, offering practical suggestions as to how the recommendations may be incorporated into everyday practice

- Extensive information on disseminating and implementing the guideline statements with the use of check-lists and action plans

- A 'lessons learned chapter' including a discussion on the limitations of the research papers examined

- A glossary of terms and full references of publications reviewed

March 1998, Occasional Paper OP41, 104 pp., ISBN 1-901242-13-7

Price $£ 20.00$ ( $£ 10.00$ to Members of the Royal College of Psychiatrists quoting Membership no.)

To order

Please send your order to the Book Sales Department, Royal College of Psychiatrists, 17 Belgrave Square, London SW1X 8PG. Tel: +44 (0) 171235 2351, ext. 146; Fax: +44 (0) 171259 6507; e-mail: booksales@rcpsych.ac.uk 